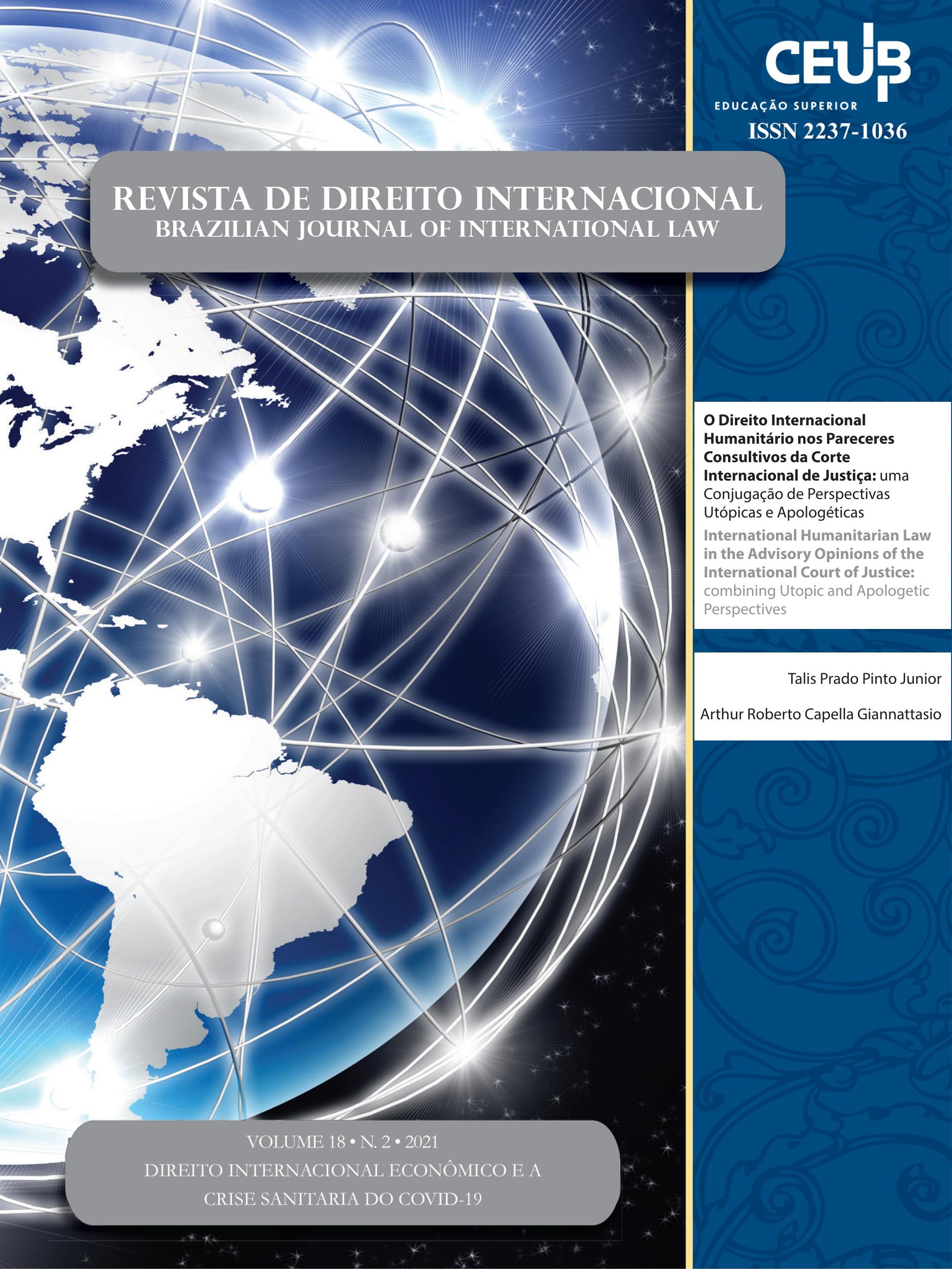




\section{Sumário}

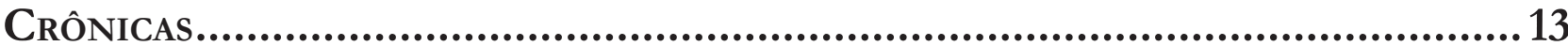

REIMAgining INTERNATIONAL RELATIONS TEACHING DURING (AND AFTER) COVID-19 ........15 Magdalena Bas

Dossiê Temático: Direito Internacional Econômico e a Crise sanitaria Do COVID-19 (INTERNATIONAL ECONOMic LaW AND THE COVID-19 SANITARY CRISIS) 19

Some QUESTIONS ABOUt INTERNATIONAL ECONOMic LAW RAISED DURING THE PANDEMIC .....21 Hervé Ascensio

International Economic LaW and the COVID-19 Sanitary Crisis: An Introduction 27 Julien Chaisse

TransparênCIA E COOPERAÇão REgUlatóRIA No COMÉRCIO INTERNACIONAL DE PRODUTOS MÉDicos PaRa a COVID-19: uMa ANÁlISE da ATUAÇão INSTITUCIONAL DA OMC E DAS NOTIFICAÇõES do Brasil EM OBSERVÂNCIA AOS ACordos TBT E SPS .35

Magali Favaretto Prieto Fernandes e Michelle Ratton Sanchez Badin

O DEVER HUMANO DE PROMOÇÃo DA SAÚDE: A AVIAÇÃo COMERCIAL INTERNACIONAL EM PERÍODOS DE CALAMIDADE SANITÁRIA E DO RETORNO À NORMALIDADE .56

Thiago de Oliveira Frizera, Luisa Cortat Simonetti Gonçalves e Adriano Sant'Ana Pedra

Police Powers Doctrine: a reliable State Defense in times of Covid-19?.... .73 Thomas Lehmann

A inexistênCia do Controle preventivo legislativo de Convencionalidade da Medida Provisória n. ${ }^{\circ} 936 / 2020$ .91

Danilo Garnica Simini, Gabriel Carvalho Moreira e Rafaela Souza Machado 
A Critical analysis of the implications of Covid-19 on piracy off the Nigerian COAST

Kalu Kingsley Anele

The COVID-19 PANDEMIC AS AN IMPELlER FOR THE AGgRAVATION OF MARINE PLASTIC POLLUTION AND ECONOMIC CRISIS: THE REVERSE EFFECT OF HEALTH PROTECTION MEASURES ON HUMAN LIVES 135

Adriana Isabelle Barbosa Lima Sá Leitão e Tarin Cristino Frota Mont’Alverne

Artigos sobre outros temas

O Direito Internacional Humanitário nos Pareceres Consultivos da Corte Internacional de Justiça: uma Conjugação de Perspectivas Utópicas e Apologéticas 156

Talis Prado Pinto Junior e Arthur Roberto Capella Giannattasio

Contesting immunities in the International Criminal Court: an analysis of the RUlings of the Pre-Trial Chambers and the Appeals Chamber in Al Bashir Case and its OUTCOMES. 171

Luisa Giannini e Roberto Vilchez Yamato

Rumo à Profissionalização da Prevenção de Controvérsias nos Acordos de CooperaÇão e Facilitação de InVEstimentos (ACFIs) do Brasil? 191

Nitish Monebhurrun e Leonardo Vieira Arruda Achtschin

THE PREVENTIVE CHARACTER OF DISASTER LAW: TAX INCENTIVES IN ENVIRONMENTAL, SOCIAL, AND GOVERNANCE (ESG) INVESTMENTS AS A RISK MITIGATION MECHANISM 212

Daniel Dela Coleta Eisaqui e Deilton Ribeiro Brasil

A URGÊNCIA DE UM MODELO DE GOVERNANÇA INTERNACIONAL DA ÁGUA: ELEMENTOS PARA A DISCUSSÃO

José Irivaldo Alves Oliveira Silva

O FIM DA HIERARQUIA SUPRALEgAL DOS TRATADOS INTERNACIONAIS: ANÁLISE DA ADI N.O 5.543/2020-DF: À luZ dA TeOria ARgumentativa de Neil Maccormick. 
Os DIREITOS HUMANOS FRENTE À NORMATIVIDADE “IMPERIAL" E A RESPONSABILIDADE DAS EMPRESAS TRANSNACIONAIS POR VIOLAÇÃO AOS DIREITOS HUMANOS NA ERA DO “IMPÉRIO” 280

Fernando Hoffmam e Jose Luis Bolzan de Morais

O RECONHECIMENTO FACIAL NAS SMART CITIES E A GARANTIA DOS DIREITOS À PRIVACIDADE E À PROTEÇÃO DE DADOS PESSOAIS.. 302

Diogo Dal Magro e Vinícius Borges Fortes

O DESENVOLVIMENTO HISTÓRICO DA PROSCRIÇÃo DO DESAPARECIMENTO FORÇADO DE PESSOAS E sua fenomenologia no Direito Penal Internacional e no Direito Internacional dos Direitos Humanos

Marcus Vinícius Xavier de Oliveira

CONSTITUCIONALISMO COOPERATIVO GLOBAL E DIREITO INTERNACIONAL PRIVADO: INSTRUMENTOS PARA UMA GOVERNANÇA DE DIREITO TRANSNACIONAL NA INTEGRAÇÃO. 362

Anderson Vichinkeski Teixeira, Roberto Correia da Silva Gomes Caldas e Luciane Klein Vieira

Proteção da inovação pela aplicaÇão do Direito da ConcorrênCia da União Europeia: ANÁLISE DA INDÚSTRIA FARMACÊUTICA.

Pablo Leurquin 


\title{
O Direito Internacional Humanitário nos Pareceres Consultivos da Corte Internacional de Justiça: uma Conjugação de Perspectivas Utópicas e Apologéticas
}

\author{
International Humanitarian Law in the \\ Advisory Opinions of the International Court \\ of Justice: combining Utopic and Apologetic \\ Perspectives
}

Talis Prado Pinto Junior**

Arthur Roberto Capella Giannattasio***

\section{Resumo}

O século XX é marcado pela crescente institucionalização do Direito Internacional (DI);seja pela positivação de normas internacionais em Tratados, seja pela criação e difusão de tribunais internacionais. Constituído no século XIX, o Direito Internacional Humanitário (DIH) acompanhou este duplo movimento: a partir da segunda metade do século XX, o DIH se consolidou como instrumento jurídico positivado para regular conflitos armados internacionais e não internacionais e foi invocado em decisões do principal órgão judicial internacional - a Corte Internacional de Justiça (CIJ). Contudo, é importante avaliar os limites desta dupla institucionalização do DIH no século XX. A partir de uma abordagem qualitativa de fontes primárias (análise documental) e secundárias (revisão bibliográfica), este artigo examina como a CIJ mobilizou o DIH nos pareceres consultivos em que esse ramo do DI foi o cerne das questões examinadas (Legalidade da Ameaça do Uso ou do Uso de Armas Nucleares e Consequências Jurídicas da Edificação de um Muro no Território Palestino Ocupado). A fim de compreender, criticamente, a institucionalização do DIH, as informações reunidas foram analisadas de acordo com a distinção conceitual apologia versus utopia, formulada por Martti Koskenniemi. Foi possível identificar que a CIJ usa o DIH combinando perspectivas utópicas e apologéticas em seus pareceres consultivos, suscitando um posicionamento ambíguo em torno do suposto progresso encontrado na realização concreta do DIH por meio do tribunal.

Palavras-chave: Direito Internacional Humanitário; Corte Internacional de Justiça; Apologia e Utopia; Progresso no Direito Internacional.

\section{Abstract}

The 20th century is characterized by the growing institutionalization of International Law (IL) - either by the affirmation of international norms in Treaties, or by the creation and diffusion of international courts. Establi- 
shed in the 19th century, International Humanitarian Law (IHL) followed this double movement: from the second half of the 20th century onwards, IHL became a legal instrument established to regulate international and non-international armed conflicts and was invoked in decisions of the principal international judicial body - the International Court of Justice (ICJ). However, it is important to assess the limits of this dual institutionalization of IHL in the 20th century. Using a qualitative approach to primary (document analysis) and secondary (literature review) sources, this article examines how the ICJ mobilized IHL in advisory opinions in which this branch of IL was at the heart of the issues examined (Legality of Threat of Use or the Use of Nuclear Weapons and Legal Consequences of Building a Wall in the Occupied Palestinian Territory). In order to critically assess the institutionalization of IHL, the information gathered was analyzed according to the conceptual distinction apologia versus utopia formulated by Martti Koskenniemi. It was possible to identify that the ICJ uses IHL combining utopian and apologetic perspectives in its advisory opinions, raising an ambiguous position concerning the so-called progress achieved by the institutionalization of the IHL while implemented by the Court.

Keywords: International Humanitarian Law; International Court of Justice; Apology and Utopia; Progress in International Law.

\section{Introdução}

É conhecido o diagnóstico de que o Direito Internacional (DI) teria encontrado, no século XX, maiores condições para se afirmar institucionalmente enquanto padrão regulador das relações internacionais. Com efeito, o século XX teria realizado duas grandes conquistas no passo de afirmação e consolidação do DI: de um lado, a codificação e a positivação de normas jurídicas internacionais costumeiras ${ }^{1}$, e, de outro lado, o adensamento jurídico das relações internacionais por meio da instituição de Organizações Internacionais $(\mathrm{OIs})^{2}$ e, principalmente, de Tribunais Internacionais ${ }^{3}$.

CASELLA, Paulo. Fundamentos do direito internacional pós-moderno. São Paulo: Quartier Latin, 2008.

2 TOURME-JOUANNET, Emmanuelle. Le Droit International. Paris: PUF, 2016.

3 TRINDADE, Antônio. Os tribunais internacionais contemporâneos.
Leituras contemporâneas têm suscitado críticas a esse discurso de suposto progresso da ordem internacional em virtude dessa dupla institucionalização durante o século $\mathrm{XX}^{4}$. Enquanto alguns autores denunciam como imoderada a crença na exclusividade de os Tribunais Internacionais solucionarem juridicamente os conflitos de maneira estável ${ }^{5}$, outros apontam esses espaços institucionalizados como lugares privilegiados de uma racionalidade jurídica ocidental ${ }^{6}$ e, por isso mesmo, favorável a um melhor posicionamento estratégico de países do Norte Global em termos teóricos ${ }^{7}$ e práticos ${ }^{8}$.

Outros autores enfatizam que a própria racionalidade regulatória de determinados temas em Tratados se orienta por um padrão terminológico ambíguo, o qual tem efeitos aparentemente contraditórios na condução concreta de questões sensíveis para as relações internacionais ${ }^{9}$. É sobre essa última crítica ao discurso sobre um progresso vivenciado pelo DI em virtude de sua institucionalização no século XX que este texto se debruça, o que será feito a partir de uma análise da aplicação das normas do Direito Internacional Humanitário (DIH).

Criado em meados do século XIX, o DIH corresponde ao conjunto de regras que regulam as condições vigentes em conflitos armados internacionais, não internacionais e não internacionais, mas internacionalizados, no que se refere a seres humanos, a meios a serem utilizados e a alvos não autorizados ${ }^{10}$. Longe de ser um instrumento perfeito e completamente eficaz, o DIH prevê um mínimo de regulação voltado a tentar minimizar o sofrimento e os impactos causados pelos conflitos armados. Trata-se nesse sentido do direito aplicável às

Brasília: FUNAG, 2013.

4 SKOUTERIS, Thomas. The notion of progress in international law. Hague: TMC, 2010.

5 ONUMA, Yasuaki. Direito internacional em perspectiva transcivilizacional. Belo Horizonte: Arraes, 2016.

6 KOSKENNIEMI, Martti. What Should International Lawyers Learn from Karl Marx? Leiden Journal of International Law, v. 17, n. 2, p. 229-24, 2004.

GIANNATTASIO, Arthur, Débora DREZZA \& Maria Wehby. In / On Applied Legal Research: Pragmatic Limits to the Impact of Peripheral International Legal Scholarship via Policy Papers. Leiden Journal of International Law, v. 34, n. 3, 2021.

8 PAHUJA, Sundhya. The Postcoloniality of International Law. Harvard International Law Journal, v. 46, n. 2, p. 459-69, 2005.

9 KOSKENNIEMI, Martti. Entre a Apologia e a Utopia: A Política do Direito Internacional. Revista de Direito Internacional, v. 15, n. 1, p. 5-29, 2018 e, do mesmo autor, A Política do Direito Internacional: 20 Anos Depois. Revista de Direito Internacional, v. 15, n. 1, p. 30-40, 2018.

10 ALMEIDA, Guilherme. A proteção da pessoa bumana no direito internacional. São Paulo: CLA, 2018. 
pessoas e bens relevantes durante o conflito armado (jus in bellum), e não de normas relativas ao direito de usar a força nas relações internacionais - o direito à guerra (jus ad bellum). ${ }^{11}$

O DIH acompanhou o movimento geral de institucionalização do DI no século XX. Além de sua sistematização nas Convenções de Genebra de 1949 e em seus Protocolos Adicionais de 1977, consolidou-se institucionalmente sua aplicabilidade por meio de 3 (três) mecanismos internacionais: (i) 2 (dois) sediados na Haia (Países Baixos), a saber, a Corte Internacional de Justiça (CIJ) e o Tribunal Penal Internacional (TPI) ${ }^{12}$, e (ii) 1 (hum) sediado em Genebra (Suíça), o Comitê Internacional da Cruz Vermelha (CICV) ${ }^{13}$. Este texto se debruça, especificamente, sobre a $\mathrm{CIJ}$, mais precisamente sobre o exercício de sua função consultiva quando se manifestou sobre o $\mathrm{DIH}^{14}$.

Estudos anteriores já analisaram normas do DIH a partir de perspectiva similar. Ao identificarem o caráter indeterminado de regras relativas a direitos e deveres de potências ocupantes, eles apontaram que a mobilização desse conjunto normativo está condicionada a variações de interpretação instrumental por parte de estados e por organismos de OIs marcados por alto teor de politicidade ${ }^{15}$.

Ao examinar como outros segmentos do DIH são mobilizados em um Tribunal Internacional, este texto avança a discussão por focar em outro tipo de espaço internacional institucionalizado. Tribunais Internacio-

\footnotetext{
11 OKIMOTO, Keiichiro. The Distinction and Relationship between Jus ad Bellum and Jus in Bello. Oxford/Portland: Hart, 2011.

12 O TPI é responsável por julgar pessoas acusadas de crimes de guerra, genocídio, crimes contra a humanidade e crimes de agressão (art. $5^{\circ}, 6^{\circ}, 7^{\circ}$ e $8^{\circ}$ do Estatuto do TPI).

13 O CICV não apenas defende as vítimas de tais conflitos, mas também exerce os papéis de aprimoramento das normas do DIH e de fiscal dos estados que ratificaram as Convenções de Genebra de 1949 e se comprometeram a observar as regras do DIH (art. 142 da IV Convenção de Genebra de 1949).

14 Os pareceres consultivos consistem na opinião da Corte em determinado assunto requisitado por um país membro das Nações Unidas ou órgão legitimado pelo artigo 96 da Carta da ONU (órgão reconhecido pela Assembleia Geral das Nações Unidas). Por serem uma opinião, não possuem caráter vinculante. Essa natureza jurídica dos pareceres consultivos é de suma importância para a compreensão da efetividade do DIH assegurada por mecanismos judiciais internacionais

15 RORIZ, João; VEÇOSO, Fabia; TASQUETO, Lucas. A administração de territórios ocupados: indeterminação das normas de direito internacional humanitário? Revista de Direito Internacional, v. 10, n. 2, p. 183-195, 2013.
}

nais têm sua legitimidade reconhecida pelo fato de fundamentarem suas manifestações em normas jurídicas $\operatorname{positivas}^{16}$, as quais são trabalhadas por juristas independentes e imparciais ${ }^{17}$ — estes, por sua vez, são especialistas cuja expertise consiste em recorrer a técnicas de argumentação consolidadas pela tradição jurídica ${ }^{18}$. Contudo, este artigo salienta que, mesmo nesses espaços privilegiados da técnica jurídica, a politicidade na mobilização das regras de DIH não desaparece. Mais do que apontar politicidade na instituição da CIJ — como ocorre em discussões sobre a construção de qualquer Tribunal Internacional ${ }^{19}$, este texto diagnostica haver uma politicidade na própria técnica jurídica que trabalha, argumentativamente, os termos da legalidade estabelecida pelo $\mathrm{DIH}^{20}$ — situação que, inclusive, não é exclusiva deste ramo do $\mathrm{DI}^{21}$.

Para tanto, este artigo foi dividido em 3 (três) partes.

Na primeira parte (2), apresentam-se e justificam-se os materiais utilizados (fontes primárias e secundárias) para coleta das informações pertinentes (2.1), explicitam-se os critérios de análise das fontes primárias levantadas (2.2), apresenta-se e descreve-se o par conceitual utopia versus apologia e discutem-se os limites epistemológicos e metodológicos derivados da adoção do marco teórico formulado por Martti Koskenniemi (2.3). Na segunda parte (3), apresentam-se os resultados da pesquisa, a partir da descrição e da análise dos 2 (dois) casos selecionados em 2.1 e analisados de acordo com os

16 KELSEN, Hans. Pąpelo Direito. São Paulo: Martins Fontes, 2010. 17 FERNANDES, Raul. The United States and the Permanent Court of International Justice. New York: American Foundation, 192?.

18 ALEXY, Robert. Teoria da Argumentação Jurídica. São Paulo: Landy, 2001; VIEHWEG, Theodor. Tópica e Jurisprudência. Porto Alegre: Sergio Antonio Fabris, 2008.

19 GIANNATTASIO, Arthur. A juridificação de conflitos políticos no direito internacional público contemporâneo: uma leitura política da paz pelo direito de Hans Kelsen a partir do pensamento político de Claude Lefort, Revista de Direito Internacional, v. 12, p. 57-76, 2016, e, do mesmo autor, A Favor de uma Corte Latino-Americana de Justiça - Uma Reação sobre a Legalidade e a Legitimidade de seu Desenho Institucional, Revista de Direito Internacional, v. 17, p. $14-$ 18, 2020. V. ainda GIANNATTASIO, Arthur; BEZERRA, Tainá; BANNWART, Elizabeth; DREZZA, Débora; BUCHLER, Jéssica; CARDOSO, Giovana; OLIVEIRA, Breno. International Constitutional Court: rise and fall of an international debate. Revista de Direito Internacional, v. 16, p. 130-146, 2019.

20 KOSKENNIEMI, Martti. The Fate of Public International Law: Between Technique and Politics. Modern Law Review, v. 70, n. 1, p. 1-30, 2008.

${ }^{21}$ KOSKENNIEMI, Martti. A Política do Direito Internacional: 20 Anos Depois. Revista de Direito Internacional, v. 15, n. 1, p. 30-40, 2018. 
critérios descritos e 2.2. $\mathrm{Na}$ terceira parte (4), interpretam-se os casos analisados com base no par conceitual utopia versus apologia apresentado em 2.3 e suscitam-se as consequências relativas à ambiguidade do tratamento dado ao DIH pela Corte.

Espera-se com isso contribuir para uma agenda de pesquisa sobre DIH que, mais do que simplesmente se restringir a compreensão normativa em torno desse ramo do DI, seja capaz de exercer um raciocínio crítico ${ }^{22}$ que deixe de lado a ideologia veiculada pelo demasiado otimismo a respeito do discurso do suposto progresso atingido pelo DI contemporâneo por meio de sua institucionalização ao longo do século $\mathrm{XX}^{23}$.

\section{Materiais e métodos utilizados}

\subsection{Pesquisa qualitativa baseada em fontes primárias e secundárias}

O presente trabalho se baseia em uma pesquisa qualitativa derivada de coleta e análise de fontes primárias (análise documental) e de fontes secundárias (revisão bibliográfica).

As fontes primárias consistem nos pareceres consultivos proferidos pela CIJ sobre DIH. A escolha desse órgão deriva do fato de esta Corte ser o principal judiciário das Nações Unidas (ONU), razão pela qual suas decisões e seus pareceres são reconhecidos como aptos a homogeneizar o DIH frente a uma possível fragmentação do DI por diferentes órgãos regionais aplicadores do $\mathrm{DIH}^{24}$. Nesse particular, não se pode ignorar que a Corte Interamericana de Direitos Humanos já aplicou

\footnotetext{
22 A relevância de promover abordagens críticas no pensamento brasileiro em DI é enfatizada por inúmeros estudos recentes; nesse sentido, v., entre outros, Arthur GIANNATTASIO. Fundamentos de uma análise sociológica crítica das instituições jurídicas internacionais: negatividade e política na metodologia dos estudos em Direito Internacional no Brasil. Revista Brasileira de Estudos Políticos, v. 116, p. 113-158, 2018, e SANCTIS, Adriane. América Latina em Continuidades e Rupturas. Revista de Direito Internacional, v. 14, n. 3, p. 285-9, 2017.

23 SKOUTERIS, Thomas. The Notion of Progress in International Law. Hague: TMC, 2010.

24 RAIMONDO, Fabián The International Court of Justice as a Guardian of the Unity of Humanitarian Law. Leiden Journal of International Law, v. 20, n. 3, p. 593-611, 2007.
}

o DIH à luz de manifestações oficiais da CIJ sobre o tema ${ }^{25}$.

Entretanto, por ser um órgão de análise geral da ONU, inúmeras são as matérias examinadas pela CIJ. O presente texto se debruçou, apenas, sobre os pareceres consultivos produzidos pela Corte, a fim de verificar em quais deles temas relacionados a DIH foram trabalhados diretamente pela CIJ. A ênfase em pareceres consultivos - e não em sentenças — deriva de 2 (dois) motivos principais, a saber:

(i) do ponto de vista metodológico, estudos anteriores mostraram que uma análise de pareceres consultivos é importante, pois permite revelar e discutir aspectos técnico-jurídicos outros nas manifestações da $\operatorname{Corte}^{26}$, o que diversifica os espectros de análise jurídica e torna mais rico e complexo o leque de tópicas a serem investigadas em DI, buscando outras questões além daquelas usualmente enfatizadas em estudos voltados a debater de forma central os fundamentos de decisões judiciais; $\mathrm{e}$

(ii) do ponto de vista de coerência teórica deste estudo, é importante perceber que, sob uma perspectiva formal, esses documentos em si incorporam e escancaram a própria ambiguidade jurídica examinada por este texto - uma oscilação entre perspectivas apologéticas e utópicas ${ }^{27}$, a saber: um instrumento normativo não vinculante (parecer consultivo) que trata de matérias ius cogens.

Dentre seus 26 (vinte e seis) pareceres consultivos, somente em 7 (sete) se pôde observar, em verificação inicialmente sumária, uma discussão em torno de $\mathrm{DIH}^{28}$. Contudo, após uma análise mais minuciosa do

25 CORTE INTERAMERICANA DE DIREITOS HUMANOS. Crus Sánchez e outros v. Peru, sentença de 07 de abril de 2015: En igual sentido, la Corte Internacional de Justicia ha considerado que, "[e]n principio, el derecho a no ser privado de la vida arbitrariamente se aplica también en tiempo de hostilidades. Ahora bien, para determinar si la privación de la vida es arbitraria hay que referirse a la lex specialis aplicable, a saber, el derecho aplicable en caso de conflicto armado, que tiene por objeto regir las situaciones de hostilidades $[\ldots] "$.

26 LIMA, Lucas Carlos. Da Relevância dos casos de Desarmamento Nuclear perante a Corte Internacional de Justiça. Revista de Direito Internacional, v. 14, n. 3, p. 202-15, 2017.

27 Sobre essa distinção conceitual, v. o item 2.3, infra.

28 Em ordem cronológica e tradução livre: $1^{\circ}$ Interpretação dos Tratados de Paz entre a Bulgária, Hungria e Romênia de 30 de março de 1950 (primeira fase); $2^{\circ}$ Interpretação dos Tratados de Paz entre a Bulgária, Hungria e Romênia de 18 de julho de 1950 (segunda fase); $3^{\circ}$ Reservas à Convenção para a prevenção e repressão ao crime de genocídio de 28 de maio de 1951; $4^{\circ}$ Consequências jurídicas para os Estados da presença contínua da África do Sul na Namíbia não 
material, verificou-se que somente 2 (dois) pareceres utilizaram conceitos do $\mathrm{DIH}^{29}$, a saber: (i) o parecer de 8.7.1996 sobre a Legalidade da Ameaça do Uso ou Uso de Armas Nucleares; e (ii) o parecer de 9.7.2004 acerca das Consequências Jurídicas da Edificação de um Muro no Território Palestino Ocupado. Os demais pareceres discutem principalmente outros temas - tais como soberania e interpretação de acordos de paz - e apenas tangenciam aspectos relativos a DIH - combatentes, potência ocupante, entre outros. Por esse motivo, eles foram excluídos da presente análise.

O presente texto ainda se fundamentou em fontes secundárias - tais como artigos, livros, capítulos. Estes foram levantados a partir de pesquisa realizada em repertórios de Universidades, bem como de base de dados como JSTOR, ATLA, Portal de Periódicos da CAPES e Scielo, a partir das seguintes palavras-chave: "International Court of Justice and Humanitarian Law" e "Principles of Humanitarian Law" e "International Court of Justice". O objetivo foi realizar uma revisão bibliográfica relativa a textos que discutissem o DIH e o papel dado pela CIJ no tratamento do DIH.

\subsection{Critérios de análise das fontes primárias}

O método de análise dos pareceres seguiu em torno das seguintes categorias: (i) dispositivos legais e costumeiros utilizados, (ii) interpretação dada pela Corte a tais dispositivos, e (iii) efeitos de tais interpretações na consulta demandada. Tais aspectos foram selecionados por atenderem ao enfoque do presente trabalho: estudo de como as normas humanitárias são interpretadas e aplicadas pela CIJ.

Foram construídas, assim, 2 (duas) tabelas, uma para cada parecer. Em cada tabela, foram inseridas informações relativas a: (i) normas e princípios invocados, (ii) o texto da norma internacional positivada, e (iii) a

obstante a resolução 276(1970) do Conselho de Segurança, de 21 de junho de 1971; $5^{\circ}$ Legalidade da utilização de armas nucleares por um Estado em conflito armado, de 08 de julho de 1996; $6^{\circ}$ Legalidade da ameaça do uso ou do uso de armas nucleares, de 08 de julho de 1996 e; $7^{\circ}$ Consequências jurídicas da edificação de um muro em território Palestino Ocupado, de 09 de julho de 2004.

29 Os pareceres selecionados abordam as fontes tradicionais do Direito Internacional e do DIH: tratados internacionais gerais e específicos sobre certa situação, a Convenção de Viena sobre o Direito dos Tratados de 1969, Convenções de Genebra, a Carta das Nações Unidas, o artigo 38 do Estatuto da própria Corte Internacional de Justiça e, principalmente, as Convenções da Haia acerca do DIH. respectiva interpretação dada pela CIJ. A tabulação foi realizada porque esse instrumento de pesquisa permite visualizar mais rapidamente a relação artigo-interpretação estabelecida pela CIJ. Para melhor compreensão da tabulação, a Tabela 1 reproduz o filtro analítico utilizado para examinar o parecer no caso sobre Legalidade da Ameaça do Uso ou Uso de Armas Nucleares é feita a seguir.

\begin{tabular}{|c|c|c|}
\hline $\begin{array}{l}\text { Norma } \\
\text { invocada }\end{array}$ & $\begin{array}{l}\text { Conteúdo da } \\
\text { norma }\end{array}$ & $\begin{array}{l}\text { Interpretação } \\
\text { pela CIJ }\end{array}$ \\
\hline $\begin{array}{l}\text { Opinio juris acerca } \\
\text { do uso de armas } \\
\text { nucleares }\end{array}$ & $\begin{array}{l}\text { Direito Consue- } \\
\text { tudinário }\end{array}$ & $\begin{array}{l}\text { Corte não sabe } \\
\text { concluir se o não } \\
\text { uso de armas nu- } \\
\text { cleares constitui } \\
\text { uma opinio juris. }\end{array}$ \\
\hline $\begin{array}{l}\text { IV Convenção da } \\
\text { Haia de } 1907\end{array}$ & $\begin{array}{l}\text { Citada como um } \\
\text { todo Interdita } \\
\text { "o emprego de } \\
\text { armas, projéteis } \\
\text { ou materiais } \\
\text { próprios a causar } \\
\text { maus supér- } \\
\text { fluos". }\end{array}$ & $\begin{array}{l}\text { Citada somente } \\
\text { como argumento } \\
\text { de autoridade. } \\
\text { Não é desenvol- } \\
\text { vida. }\end{array}$ \\
\hline $\begin{array}{l}\text { Princípios "cardi- } \\
\text { nais" do DIH }\end{array}$ & $\begin{array}{l}\text { Distinção civil- } \\
\text { militar; vedação a } \\
\text { mal supérfluo. }\end{array}$ & $\begin{array}{l}\text { Vedação a armas } \\
\text { que não fazem } \\
\text { essa distinção. } \\
\text { Estados não } \\
\text { possuem escolha } \\
\text { ilimitada sobre } \\
\text { tipos de armas. }\end{array}$ \\
\hline $\begin{array}{l}\text { Cláusula Martens } \\
\text { - II Convenção } \\
\text { da Haia de } 1899 \\
\text { - atualmente no } \\
\text { art. } 1^{\circ}, \sqrt{ } 2^{\circ} \text {, pro- } \\
\text { tocolo adicional I } \\
\text { de } 1977\end{array}$ & $\begin{array}{l}\text { “Nos casos } \\
\text { não previstos } \\
\text { pelo presente } \\
\text { protocolo e por } \\
\text { outros acordos } \\
\text { internacionais, } \\
\text { os civis e com- } \\
\text { batentes ficam } \\
\text { sob a salvaguarda } \\
\text { e sob o império } \\
\text { dos princípios } \\
\text { das gentes, tais } \\
\text { que resultam das } \\
\text { práticas estabele- } \\
\text { cidas, princípios } \\
\text { de humanidade } \\
\text { e exigências } \\
\text { da consciência } \\
\text { pública." }\end{array}$ & $\begin{array}{l}\text { Vedação à in- } \\
\text { distinção civil- } \\
\text { militar, às armas } \\
\text { de sofrimento } \\
\text { inútil (superiores } \\
\text { à consecução de } \\
\text { um fim militar } \\
\text { legítimo), consi- } \\
\text { derações elemen- } \\
\text { tares de huma- } \\
\text { nidade (acórdão } \\
\text { de } 9 / 04 / 1949 \text { - } \\
\text { Detroit de Cor- } \\
\text { four - princípios } \\
\text { intransponíveis } \\
\text { do DIH). }\end{array}$ \\
\hline
\end{tabular}




\begin{tabular}{|c|c|c|}
\hline $\begin{array}{l}\text { Norma } \\
\text { invocada }\end{array}$ & $\begin{array}{l}\text { Conteúdo da } \\
\text { norma }\end{array}$ & $\begin{array}{l}\text { Interpretação } \\
\text { pela } \mathrm{CIJ}\end{array}$ \\
\hline $\begin{array}{l}\text { Resolução } \\
1653 \text { (XVI) de } \\
\text { 24/11/1961 da } \\
\text { Assembleia Geral } \\
\text { das Nações Uni- } \\
\text { das (AGNU) }\end{array}$ & $\begin{array}{l}\text { Cita a resolução } \\
\text { como um todo } \\
\text { na ilegalidade } \\
\text { do uso de armas } \\
\text { nucleares - } 1^{\text {a }} \\
\text { resolução acerca } \\
\text { da questão. }\end{array}$ & $\begin{array}{l}\text { Instrumento de } \\
\text { soft law - início de } \\
\text { uma opinio juris. }\end{array}$ \\
\hline $\begin{array}{l}\text { Direito consuetu- } \\
\text { dinário específico } \\
\text { às armas nucle- } \\
\text { ares }\end{array}$ & Não se aplica. & $\begin{array}{l}\text { Várias resoluções } \\
\text { da AGNU reco- } \\
\text { mendam a reali- } \\
\text { zação de tratados } \\
\text { para vedar o uso } \\
\text { de armas nuclea- } \\
\text { res - nascimento } \\
\text { de uma opinio } \\
\text { juris. }\end{array}$ \\
\hline $\begin{array}{l}\text { Convenção de } \\
10 / 10 / 1980 \text { de } \\
\text { Interdição ou } \\
\text { Limitação de } \\
\text { certas Armas que } \\
\text { Produzem Trau- } \\
\text { ma Excessivo ou } \\
\text { Discriminatório }\end{array}$ & $\begin{array}{l}\text { Convenção citada } \\
\text { como um todo. }\end{array}$ & $\begin{array}{l}\text { Instrumento } \\
\text { utilizado como } \\
\text { argumento de } \\
\text { autoridade. }\end{array}$ \\
\hline
\end{tabular}

Fonte: os próprios autores.

\subsection{Marco teórico: direito internacional entre apologia e utopia}

A oposição conceitual entre utopia e apologia é a base da reflexão teórica desenvolvida pelo presente artigo. A ideia é pensar a interpretação da CIJ sobre normas de DIH com base nessa distinção, a qual foi identificada por Martti Koskenniemi como elemento característico do Direito Internacional a partir do século XIX ${ }^{30}$.

A distinção foi escolhida em virtude de ela fornecer elementos para construir uma consciência crítica em torno da indeterminação que marca os dispositivos normativos do DIH, como em qualquer ramo do DI. $\mathrm{Na}$ perspectiva do autor mencionado, a tradição jurídica ocidental europeia liberal é fundada em uma técnica regulatória que prevê normas de conteúdo indeterminado. Essa fórmula geral promoveria uma abertura que, enquanto solução de compromisso, atenderia a expecta-

30 KOSKENNIEMI, Martti. Entre a Apologia e a Utopia: A Política do Direito Internacional. Revista de Direito Internacional, v. 15, n. 1, p. 5-29, 2018. tivas contraditórias em virtude da precisa generalidade da previsão normativa ${ }^{31}$.

Nesses termos, a indeterminação das regras de DI estabeleceria um elevado grau de maleabilidade dos sentidos que lhes poderiam ser atribuídos. A regulação estabelecida pelo DI se encontraria, assim, em uma zona cinzenta, cuja ambiguidade na formulação de promessas amplas seria suprida por juristas treinados em técnica jurídica consolidada. Contudo, Martti Koskenniemi identifica que a mobilização argumentativa realizada por juristas tende a oscilar entre 2 (duas) orientações: uma utópica, outra apologética ${ }^{32}$.

Uma orientação utópica tende a enfatizar uma independência do DI em relação à vontade dos Estados. Essa perspectiva compreende que as regras jurídicas estabeleceriam uma normatividade dotada de força própria, o que fundaria a convicção de ser este ramo do Direito capaz de dirigir e de modificar as maneiras de agir e de pensar soberanas de tais sujeitos de DI no sentido de atender os objetivos dessas regras jurídicas. Assim, a normatividade do DI operaria como ideal norteador de promessas inesgotáveis de realização e de ampliação de liberdade e de igualdade individuais e coletivas.

Por seu turno, uma orientação apologética tende a visualizar uma maior relação de dependência do DI em relação à vontade dos Estados. Fundada em uma percepção de concretude da verdade efetiva das relações internacionais, juristas tenderiam a reconhecer que, em muitos casos, o DI se retrairia "desculposamente" (apologetically) diante das incontroláveis e imponderáveis manifestações de poder dos Estados. A realidade da estrutura internacional estabeleceria, assim, uma dinâmica em que concretamente o DI não seria capaz de influenciar, de forma integral, as decisões soberanas dos Estados.

Nessa perspectiva, a argumentação jurídica que modularia os diferentes sentidos possíveis das normas de DI se moveria incessantemente dentro de 2 (dois) padrões de justificativa: um padrão descendente, que "privilegia normatividade sobre concretude (tradução livre)", e um padrão "ascendente, o qual faz o oposto

31 KOSKENNIEMI, Martti. What Should International Lawyers Learn from Karl Marx? Leiden Journal of International Law, v. 17, n. 2, p. 229-24, 2004.

32 KOSKENNIEMI, Martti. Entre a Apologia e a Utopia: A Política do Direito Internacional. Revista de Direito Internacional, v. 15, n. 1, p. 5-29, 2018. 
(tradução livre)" "33. Assim, nos distintos espaços institucionalizados no interior dos quais normas de DI são invocadas para solucionar conflitos, juristas recorreriam à expertise consolidada em sua área de conhecimento para justificar um sentido dentro de padrão descendente ou ascendente. Por isso mesmo, entende-se que essa oscilação pode ocorrer também no uso das normas de DIH pela CIJ, o que será analisado nos itens a seguir.

Contudo, é importante realizar, ainda, uma rápida consideração sobre os limites epistemológicos e metodológicos que derivam do recurso a esse par conceitual.

Do ponto de vista epistemológico, ao recorrer ao marco teórico de Martti Koskenniemi, este texto se insere em uma específica leitura crítica do DI. Apesar de haver hoje uma profusão de diferentes abordagens críticas desse ramo do Direito ${ }^{34}$, este artigo se inscreve, de maneira consciente, no arco de questões em torno do problema da relação entre Política e DI apresentado pela abordagem crítica proposta pelo autor.

Não se trata de realizar uma genealogia das fundações do pensamento de Martti Koskenniemi ${ }^{35}$. Mas de reconhecer que ele apresenta uma certa leitura que trabalha precisamente em torno da "estrutura retórica do Direito (tradução livre)", a qual se concentra em compreender "padrões de argumentação (tradução livre)" deste campo intelectual ${ }^{36}$. Nesse sentido, há uma preocupação desse marco teórico em analisar a linguagem empregada por juristas nos momentos de justificar a construção de sentidos a serem atribuídos a textos normativos $^{37}$, a fim de compreender as condições que marcam as formas possíveis de argumentação ${ }^{38}$.

\footnotetext{
33 KOSKENNIEMI, Martti. Entre a Apologia e a Utopia: A Política do Direito Internacional. Revista de Direito Internacional, v. 15, n. 1, p. 5-29, 2018.

34 BADIN, Michelle; MOROSINI, Fabio; GIANNATTASIO, Arthur (org.). Direito internacional: leituras críticas. São Paulo: Almedina, 2019.

35 Alguns autores buscaram apresentar essa reflexão, como RASULOV, Akbar. From apology to utopia and the inner life of international law. Leiden Journal of International Law, v. 29, n. 3, p. 641-666, 2016, e HASKELL, John. From apology to utopia's condition of possibility. Leiden Journal of International Law, v. 29, n. 3, p. 667-676, 2016.

36 KENNEDY, David. The Last Treatise: Project and Person (Reflections on Martti Koskenniemi's From Apology to Utopia). German Law Journal, v. 7, n. 2, 2006, p. 982.

37 SANCTIS, Adriane. América Latina em Continuidades e Rupturas. Revista de Direito Internacional, v. 14, n. 3, p. 285-9, 2017.

38 KENNEDY, David. The Last Treatise: Project and Person (Reflections on Martti Koskenniemi's From Apology to Utopia). German Law Journal, v. 7, n. 2, 2006, p. 985.
}

É por esse motivo que, ao analisar as manifestações da CIJ sobre DIH, o presente artigo coteja textos normativos com as manifestações da Corte. A ideia consistiu em compreender, conceitualmente, o esforço argumentativo da Corte em torno do par conceitual, a fim de identificar e nomear as formas que a $\mathrm{CIJ}$ encontrou para mobilizar conjuntamente as duas orientações assinaladas por Martti Koskenniemi na atribuição de sentido para normas de DIH para "se desculpar por o que é e prometer o que ainda pode ser (tradução livre)" 39 .

Do ponto de vista metodológico, deve-se estar consciente de que operar dentro da distinção conceitual utopia versus apologia implica, ao menos, 2 (duas) consequências para a reflexão proposta ao final deste texto.

A primeira consiste em admitir a compreensão crítica proposta por Martti Koskenniemi em torno do problema da relação entre Política e DI. Ao enfatizar o aspecto indeterminado das regras jurídicas internacionais derivadas da tradição jurídica liberal ${ }^{40}$, este artigo deixa de analisar os pareceres da CIJ com base em outra discussão proposta pelo próprio autor em torno da especialização técnica e temática do DI em virtude da fragmentação em distintas $\mathrm{OIs}^{41}$.

A segunda consiste em reconhecer algo mais simples, a saber: o estabelecimento de uma lente de análise determinada significa, por si só, restringir os termos de interpretação dos fenômenos observados. Em outros termos, se este estudo recorresse a outra linguagem para compreender as manifestações da CIJ sobre o tema ensejaria a formulação de outras conclusões. Por esse motivo, a interpretação de todo e qualquer fenômeno é, por si só, inesgotável e jamais definitiva, pois sempre realizada segundo perfis iluminados a partir das categorias utilizadas ${ }^{42}$.

Considerando-se os critérios de seleção e de coleta das fontes primárias e secundárias, as categorias de

\footnotetext{
39 KENNEDY, David. The Last Treatise: Project and Person (Reflections on Martti Koskenniemi's From Apology to Utopia). German Law Journal, v. 7, n. 2, 2006, p. 986.

40 KOSKENNIEMI, Martti. What Should International Lawyers Learn from Karl Marx? Leiden Journal of International Law, v. 17, n. 2, p. 229-24, 2004.

${ }^{41}$ KOSKENNIEMI, Martti. A Política do Direito Internacional: 20 Anos Depois. Revista de Direito Internacional, v. 15, n. 1, p. 30-40, 2018.

42 GIANNATTASIO, Arthur. Contra um Fetichismo nos Estudos Empíricos em Direito Internacional: moldura intencional e o esvaziamento significativo da empiria. Revista de Estudos Empíricos em Direito, v. 5, p. 9-24, 2018.
} 
análise das fontes primárias, as definições dos conceitos operacionais do marco teórico escolhido e os problemas epistemológicos e metodológicos que a escolha desse referencial e do respectivo par conceitual implica para o presente estudo, passa-se, assim, para a compreensão do objeto de investigação selecionado.

\section{Análise dos pareceres consultivos da CIJ envolvendo DIH}

Este item apresenta individualmente cada um dos pareceres selecionados e destaca os principais elementos relacionados às regras de DIH trabalhados pela CIJ. Será analisado, em primeiro lugar, o parecer relativo à Legalidade da Ameaça do Uso ou do Uso de Armas Nucleares (3.1) e, em segundo lugar, o parecer relativo às Consequências Jurídicas da Edificação de um Muro no Território Palestino Ocupado (3.2). A partir da compreensão dos argumentos trabalhados pela CIJ em cada caso, será mais fácil compreender como se propõe mais adiante (4.) a aplicação do par conceitual para compreender os padrões de argumentação desse Tribunal em relação à aplicação das regras de DIH.

\subsection{Legalidade da ameaça do uso ou do uso de armas nucleares (8.7.1996)}

Este parecer deriva de outro apresentado anteriormente à $\mathrm{CIJ}$ e que não teve seu mérito analisado em virtude da ausência de capacidade de pedir por parte da Requerente ${ }^{43}$. Contudo, devido à relevância da matéria, a Assembleia Geral das Nações Unidas (AGNU) solicitou à CIJ um parecer muito semelhante, o qual foi analisado pela CIJ: "seria a ameaça do uso ou o uso de armas nucleares permitido, em qualquer circunstância, pelo direito internacional? (tradução livre)".

Em sua resposta à pergunta formulada pela AGNU, depois de considerar normas de Direitos Humanos (Pacto Internacional relativo aos Direitos Civis e Políticos) e Direito Ambiental (Declaração do Rio), a CIJ se concentra em normas específicas de DIH.

\footnotetext{
43 No parecer anterior, a Organização Mundial da Saúde (OMS) havia demandado se era lícito o uso de armas nucleares, mas a CIJ decidira que a OMS não tinha capacidade postulatória (art. 96, item "a" da Carta da ONU).
}

O primeiro movimento argumentativo da CIJ é analisar se haveria um costume internacional em DIH que autorizaria ou proibiria o uso de armas nucleares como instrumentos aceitáveis em conflitos armados.

Nesse sentido, a Corte expôs que a regulação das armas nucleares era tratada com relevância pela comunidade internacional — havendo inúmeras Resoluções da AGNU recomendando a celebração de tratados sobre o tema. Por um lado, CIJ reconheceu não haver convenção que expressamente vetasse o uso ou a ameaça de uso por países detentores de armamento nuclear, não havendo, assim, um costume internacional que, nos termos do art. 38 do Estatuto da CIJ, pudesse ser reconhecido como proibindo o uso desse tipo de arma. Por outro lado, ao examinar especificamente a Resolução 1653 (XVI) de 24/11/1961 da AGNU, a Corte reconheceu que essa recomendação poderia ser um primeiro passo em direção à construção de uma opinio juris ${ }^{44} \mathrm{em}$ torno da ilicitude do uso ou da ameaça do uso de armas nucleares ${ }^{45}$.

Ainda no que se refere aos meios empregados em situações de conflitos armados, a CIJ também invocou no parecer a Convenção de Interdição ou Limitação de Certas Armas que Produzem Trauma Excessivo ou Discriminatório, celebrada em Genebra em 10 de outubro de 1980, e o Regramento da Haia de 1907 — o qual, em seu artigo 22, afirma que os beligerantes não possuem direito ilimitado de escolha quanto aos meios de causar dano ao inimigo. No mesmo sentido, a CIJ mencionou a Convenção de São Petersburgo de 1868, por meio da qual se condena o "emprego de armas que agravam inutilmente o sofrimento dos homens fora de combate ou deixem suas mortes inevitáveis (tradução livre)".

Outras normas de DIH foram mobilizadas pela Corte nesse mesmo parecer, as quais são combinadas a partir da consideração da distinção jurídica entre seres humanos envolvidos em conflitos armado: civis e combatentes.

\footnotetext{
44 Sobre opinio iuris, v. Arthur GIANNATTASIO. A Opinio Iuris Sive Necessitatis: Do Elemento Subjetivo Consuetudinário à Intersubjetividade Jurídica. In: CASELLA Paulo; RAMOS, André (Org.). Direito Internacional. São Paulo: Quartier Latin, 2009.

45 Aspecto retomado poucos anos depois, em futuras decisões da CIJ sobre temas correlatos, como discute, p. ex., Lucas Carlos LIMA. Da Relevância dos casos de Desarmamento Nuclear perante a Corte Internacional de Justiça. Revista de Direito Internacional, v. 14, n. 3, p. 202-15, 2017.
} 
A partir do art. $2^{\circ}$ da IV Convenção da Haia de 1907 - a qual interdita "o emprego de armas, projéteis ou materiais próprios a causar mal supérfluo (tradução livre)" - a CIJ argumentou que se proibiu o uso de todo e qualquer armamento que não respeitasse aquela diferença entre pessoas envolvidas em conflitos. Ao mesmo tempo, a Corte invocou a cláusula Martens norma costumeira que surgira na Conferência de Paz da Haia de $1899^{46}$, a qual estabelece que, em uma situação não regulamentada pelas partes em conflito, civis e combatentes estão "sob a proteção e o império dos princípios do direito internacional, derivado dos usos estabelecidos entre nações civilizadas, das leis humanas e das exigências da consciência pública (tradução livre)". ${ }^{47}$ No entanto, a CIJ parece ter invocado esse costume apenas como uma estratégia para justificar a aplicação das regras de DIH ao uso ou à ameaça do uso de armas nucleares.

A conclusão da CIJ ao final do parecer é nebulosa. Se a CIJ afirma que o art. $2^{\circ}, \int 4^{\circ}$ e o art. 51 da Carta das Nações Unidas não autorizam essa prática, ela afirma, também, em seguida, ser lícita essa prática se realizada conforme as exigências do DIH. Essa postura parece ter preservado um grau de indeterminabilidade na construção dos sentidos juridicamente aceitáveis de atribuição às regras de DIH.

\subsection{Consequências jurídicas da edificação de um muro no território palestino ocupado (9.7.2004)}

Este parecer consultivo também foi solicitado pela AGNU e questionou a CIJ sobre quais seriam as consequências jurídicas potencialmente derivadas da construção de um muro por Israel (potência ocupante) no território da Palestina (ocupado por Israel). Após a análise dos critérios referentes à admissibilidade, com base na Carta da ONU, no Pacto Internacional de Direitos Civis e Políticos e em normas de DIH, a CIJ concluiu que a ação de Israel é contrária ao DI e que esse Estado deveria pôr fim às violações.

Seguindo o recorte proposto por este texto, concentra-se a análise sobre o modo pelo qual a CIJ mobilizou

\footnotetext{
46 BERNSTORFF, Jochen. Martens Clause. In: WOLFRUM, R. The Max Planck encyclopedia of public international law. Oxford: Oxford University, 2012. v. 6.

47 TICEHURST, Rupert. The Martens Clause and the Laws of Armed Conflict. International Review of the Red Cross, n. 317, 1997.
}

as regras específicas do DIH para caracterizar as práticas de Israel no território Palestino como ações claras de uma potência ocupante que age em progressiva violação de diferentes normas de DIH.

A CIJ inicia seu esforço argumentativo invocando as regras da Convenção da Haia de 1907 e trabalhando no sentido de construir uma interpretação com base em categorias de DI geral. Em primeiro lugar, a CIJ afirmou ter a Convenção um caráter costumeiro e que, em virtude da opinio juris geral reconhecida nas disposições deste documento, a obrigatoriedade de suas regras independeria da vontade israelense. Nesses termos, mesmo sem ter ratificado essa Convenção, Israel estaria vinculado às previsões desta Convenção. Em segundo lugar, a $\mathrm{CIJ}$ entendeu que a instalação de colônias israelenses na Palestina seria uma grave violação à autodeterminação deste povo - isto é, uma violação às regras ius cogens prevista na Carta da ONU e a uma obrigação erga omnes prevista na Convenção da Haia de 1907.

A IV Convenção de Genebra de 1949 — da qual Israel e a Jordânia são signatárias — é também mobilizada pela CIJ, quem reconhece o caráter impositivo dessa Convenção em caso de ocupação, mesmo sem resistência militar por parte da população cujo território foi ocupado. Com base no art. 49 da IV, alínea 6, da Convenção de Genebra, a CIJ orienta sua interpretação no sentido de afirmar que, se a norma estabelece que a potência ocupante não poderá proceder à deportação ou à transferência de uma parte de seus próprios civis em território ocupado por ela, Israel estaria claramente violando o DI por práticas recorrentes. Essa anexação de facto por Israel de tais territórios seria, nos termos da CIJ, um "obstáculo grave ao exercício de autodeterminação pelo povo palestino, cujo direito deveria ser respeitado por Israel, enquanto potência ocupante (tradução livre)" ${ }^{48}$.

Nesses termos, os art. 43 e 46 do Regramento da Haia de 1907 são também mobilizados pela CIJ, que lhe permite reforçar e aprofundar seu entendimento. Partindo da previsão de que a potência ocupante tem o dever de tomar "todas as medidas que dependem dele para restabelecer ou assegurar, na medida do possível, a ordem e a vida públicas, sem impedimento absoluto, as

\footnotetext{
48 Parecer Consultivo de 09 de julho de 2004 da Corte Internacional de Justiça: Consequências jurídicas da edificação de um muro em território palestino ocupado, p. 137.
} 
leis em vigor no país [ocupado] (tradução livre)”49 e que, nesses termos, a propriedade privada deve ser respeitada e não confiscada, a CIJ reconhece a ilegalidade das colônias israelenses na ocupação da Palestina.

Ao se voltar, de maneira específica, sobre a mesma IV Convenção de Genebra, a CIJ amplia as bases de sua argumentação. Para tanto, ela recorre, conjuntamente, aos artigos 47, 49, 52, 53 e 59 da referida Convenção e modula o sentido jurídico de cada um eles segundo uma estrutura normativa que revela um pouco mais sobre a orientação da CIJ na aplicação das normas de DIH para o caso concreto.

Os 3 (três) primeiros artigos se destinam propriamente à proteção de pessoas em situação de conflitos armados. O primeiro define que, em nenhum caso, as pessoas do território ocupado serão privadas das garantias trazidas no presente documento, ainda que haja troca de governo por parte da nação ocupante ou uma anexação. Por seu turno, o segundo artigo estabeleceu a interdição de transferências forçadas, em massa ou individuais, bem como de deportações de pessoas protegidas fora do território ocupado para o do ocupante ou de qualquer outro país está interditado - salvo evacuações por questões humanitárias. E o terceiro artigo protege a força de trabalho da nação ocupada, ao determinar ser vedado ao país ocupante propagar medidas que visem à promoção ou à manutenção do desemprego.

O quarto artigo se destina à proteção de bens nos territórios ocupados. Nesse sentido, há uma vedação expressa à nação ocupante de destruir bens, mobiliários ou imobiliários, individuais ou coletivos de pessoas privadas, do Estado, organizações sociais e cooperativas. A norma excepciona essa proibição apenas nos casos em que tal medida for necessária para a consecução das operações militares, de maneira a minimizar o potencial destrutivo das investidas armadas sobre territórios ocupados.

Por fim, o quinto artigo estipula o elemento fundamental do DIH: o reconhecimento da garantia de livre passagem de ajuda humanitária ao país ocupado. Essa passagem livre está autorizada pelo documento precisamente por a ajuda humanitária ser feita por instituições independentes - como o CICV.

\footnotetext{
49 Parecer Consultivo de 09 de julho de 2004 da Corte Internacional de Justiça: Consequências jurídicas da edificação de um muro em território palestino ocupado, p. 185.
}

É por meio da conjugação desses dispositivos que a CIJ entende ser ilegal a construção do muro por Israel, rechaçando os argumentos israelenses de que tais medidas (i) foram necessárias para a realização dos fins militares garantidos nas Convenções de Genebra, (ii) representam legítima defesa e estado de necessidade. A CIJ conferiu um enfoque restritivo a tais instrumentos, os quais são excepcionais ${ }^{50}$ — não cabendo ao estado interessado julgar se os requisitos de sua aplicação estão presentes. Ao mesmo tempo, a Corte afirma ter havido confisco por Israel de terras férteis da Cisjordânia, a destruição de plantações, a tributação de produtos palestinos e a anexação do lençol freático ocidental da região - importante fonte de água para a Palestina ${ }^{51}$.

\section{Pareceres consultivos da $\mathrm{CIJ}$ sobre DIH: combinando apologia e utopia}

Diante da rápida apresentação acima dos pareceres examinados por este estudo (3.), esse item esmiúça e explicita os padrões de argumentação (descendente/ascendente) no interior dos quais se moveu a técnica jurídica da CIJ. Do mesmo modo que no item anterior, será analisado, em primeiro lugar, o parecer relativo à Legalidade da Ameaça do Uso ou do Uso de Armas Nucleares (4.1) e, em segundo lugar, o parecer relativo às Consequências Jurídicas da Edificação de um Muro no Território Palestino Ocupado (4.2). Isso permitirá identificar e nomear como o recurso ao DIH nesses casos expressa uma oscilação, nas condições de possibilidade de argumentação jurídica dentro da Corte, entre uma orientação utópica (propugnando pela normatividade) e uma orientação apologética (reconhecendo a concretude).

\subsection{Legalidade da ameaça do uso ou do uso de armas nucleares (8.7.1996)}

O primeiro dispositivo a ser analisado é a opinio juris. Não se trata de um conceito puramente humanitário,

\footnotetext{
50 OKIMOTO, Keiichiro. The Distinction and Relationship between Jus ad Bellum and Jus in Bello. Oxford/Portland: Hart, 2011.

51 Alguns autores enfatizam que as regras de DIH examinadas pela $\mathrm{CIJ}$ neste caso representam regra costumeira, mas que a indeterminabilidade de seu conteúdo pode ensejar abusos por Estados mais poderosos. V. nesse sentido RORIZ, João; VEÇOSO, Fabia; TASQUETO, Lucas. A administração de territórios ocupados: indeterminação das normas de direito internacional humanitário? Revista de Direito Internacional, v. 10, n. 2, p. 183-195, 2013.
} 
mas ele influencia diretamente a tratativa do tema pela CIJ. Elencado no art. 38 do Estatuto da CIJ como a "prática geral aceita como sendo o Direito", esse instituto é influenciado, inicialmente, por argumentos apologéticos. O consenso internacional acerca do que é aceito como "sendo o Direito" é variável, restando o sentido jurídico de costumes na dependência de um posicionamento estatal. Contudo, a interpretação da CIJ nesse caso parece realizar um deslocamento dessa influência apologética, de modo a ceder lugar ao argumento utópico — isto é, a uma concepção de ampliação do justo nos parâmetros dados pela própria CIJ, separada da vontade estatal.

Assim, observa-se o fenômeno descrito por Koskenniemi em que ambas as concepções realizam uma dinâmica argumentativa. Quando se verifica um Estado manipular o conceito de "prática aceita como sendo o Direito", tem-se a concretude, mais ligada a um imoderado realismo. Todavia, a CIJ utiliza o art. 38 de seu Estatuto em um sentido mais normativo, o qual é mobilizado contra Estados. Há, assim, uma busca de conciliação entre a concretude e a normatividade na modulação do sentido do instituto da opinio iuris.

Ao invocar a Resolução 1653 (XVI) de 24/11/1961 da AGNU, a CIJ trabalha esse instituto com base em influência da orientação apologética. Por não ser um instrumento vinculante e por depender exclusivamente do poder político para sua implementação, o padrão ascendente de justificação é dominante na matéria, sendo observável uma prática mais concreta do que normativa na abordagem deste documento. Por esse motivo, a orientação utópica se restringe a reconhecer nesse documento uma tendência de potencial formação, no futuro, de uma opinio juris em torno do tema.

Do mesmo modo, quando a CIJ invoca e interpreta, a Convenção de Interdição ou Limitação de Certas Armas com trauma excessivo e discriminatório de 1980, o Regramento de Haia de 1907 e a Convenção de São Petersburgo de 1868, ela o faz novamente dentro de uma dinâmica que oscila entre as duas orientações.

Com efeito, por serem tratados, esses documentos normativos vinculam as partes signatárias que os ratificaram - o que evidencia a presença dupla da normatividade e da concretude: o valor único de justiça foi escolhido pelos signatários de forma consensual. Todavia, por não regulamentar o uso ou ameaça do uso de armas nucleares, a normatividade apresentada por esses documentos não é trazida como um posicionamento final, mas como balizas para auxiliar o aplicador do DI na resolução da questão a ele formulada. Em outras palavras, se se parte da apologia ("foi o mínimo que os estados convencionaram"), a modulação dos termos dessa previsão segue tendo em mente a utopia ("é possível ampliar a realização originalmente prevista para este caso").

Mesmo a IV Convenção da Haia de 1907 interpretada pela CIJ não foge a essa oscilação, ainda que de forma distinta. Essa norma costumeira não trata taxativamente da vedação do uso e/ou ameaça de uso de armas nucleares, mas, mesmo em outros temas, é, por vezes, marcada profundamente pela concretude, pois não se verifica na prática essa Convenção como limitadora do poderio bélico dos estados ${ }^{52}$.

Por fim, ao citar a cláusula Martens - pedra angular no lastro argumentativo da CIJ, a Corte remete esse costume à aplicação dos princípios reconhecidos pelas nações civilizadas em caso de lacunas humanitárias. Desse modo, a CIJ justifica a normatividade sobre concretude: a CIJ se valeu da abrangência dessa previsão e foi capaz de construir um argumento jurídico segundo uma orientação utópica: um único valor de Justiça - o da própria CIJ — sobre o que são os valores das nações civilizadas, independentemente da vontade estatal.

\subsection{Consequências jurídicas da edificação de um muro no território palestino ocupado (9.7.2004)}

O primeiro instituto jurídico invocado neste parecer, a partir da lente DIH, é o Princípio da Autodeterminação dos Povos. Esse topos sofre influência duplamente utópica e apologética: de um lado, tem sua normatividade derivada de um valor do justo típico da sociedade ocidental, mas também é largamente utilizado mais na concretude "do real" do jogo das relações internacionais. Mas, com base nessa ambiguidade da norma, a CIJ mobiliza a técnica jurídica argumentativa para construir seu posicionamento.

\footnotetext{
52 Entretanto, como mencionado no item 3.2, supra, esta mesma Convenção foi reconhecida pela CIJ como portadora de obrigações erga omnes e, por isso, aplicada contra a vontade de Israel. Como se apontará no item 4.2, infra, essa postura da CIJ propugna nessa mesma Convenção sua normatividade em detrimento da concretude e, com isso, evidencia, de forma clara, a oscilação argumentativa entre utopia e apologia no tratamento das normas de DIH pela Corte.
} 
No que se refere à Convenção da Haia de 1907, é observável novamente a relação entre a dupla concretude e normatividade. Um prévio acordo entre partes estabelece um mínimo reconhecido consensual (apologia) - o que, por si só, não possui natureza erga omnes. Contudo, a Corte concede caráter costumeiro à Convenção e, por meio desse raciocínio, orienta utopicamente a compreensão deste documento dentro de uma chave interpretativa que reforça sua normatividade. Desse modo, para a CIJ ocorreu um processo histórico no qual a concretude cedeu lugar à normatividade e, por esse motivo, a Convenção foi utopicamente reconhecida como portando obrigações erga omnes, sendo aplicável independentemente da vontade de Israel, contra esse Estado.

Em relação à IV Convenção de Genebra, mais uma vez, a chave explicativa do costume auxilia a compreensão do esforço argumentativo da CIJ. Israel é parte signatária das Convenções e a história do país é marcada por conflitos. Nesses termos, a CIJ insere o Estado no interior do regime jurídico do Tratado precisamente a partir de argumentos que se sustentam em uma orientação apologética, a qual reconhece estar esse estado vinculado a essa norma e a seus padrões consensuais de justiça por sua própria vontade soberana.

\section{Considerações finais}

À luz de todo o exposto, observa-se que, como parte do DI, o DIH é igualmente influenciado pela ambiguidade dada pela oscilação argumentativa entre orientações utópicas e apologéticas na condução da técnica jurídica de atribuição de sentido a normas. Mesmo em processos decisórios judiciais - local por excelência de operação da expertise jurídica, e não política ${ }^{53}$, as normas não se desvencilham de seu horizonte de indeterminação regulatória e, portanto, de um certo tipo de politicidade ${ }^{54}$.

Nesses termos, entende-se que a pacificação do sentido normativo se desenvolve precisamente a partir de uma modulação interpretativa que se guia duplamente pela dinâmica de interação entre padrões ascendentes

\footnotetext{
53 KELSEN, Hans. Parpelo Direito. São Paulo: Martins Fontes, 2010. 54 KOSKENNIEMI, Martti. Entre a Apologia e a Utopia: A Política do Direito Internacional. Revista de Direito Internacional, v. 15, n. 1 , p. 5-29, 2018.
}

e descendentes de argumentação. Com isso, da criação das normas internacionais para sua aplicação, geralmente há um deslocamento incessante entre a afirmação da concretude do real (consenso entre os estados) e a afirmação da normatividade do DI (ampliação, a partir de tal consenso), e vice-versa. As divergências interpretativas na aplicação de normas internacionais ocorrem assim em um movimento pendular entre uma orientação apologética ("que se desculpa") e utópica (horizonte de possibilidades alternativas).

As normas do DIH não parecem, assim, escapar à dinâmica apologética/utópica, o que é verificável nos 2 (dois) pareceres selecionados. Passados oito anos entre um parecer e outro, a questão do muro israelense em território palestino rompe com os interesses de um dos principais aliados dos membros permanentes do Conselho de Segurança: as atitudes de Israel são declaradas ilegais, modulando por exemplo o sentido jurídico (concreto versus normativo) de um mesmo documento.

Esse processo somente é possível pela flexibilização da apologia à utopia da CIJ, um processo que tende a se reproduzir pela preferência da normatividade sobre a concretude. A anterior verificação prática de medidas estatais cede espaço à normatividade menos concreta de uma declaração não vinculante. Nesse jogo duplo, o sentido normativo do DIH se torna progressivamente mais palpável, ainda que suas normas se mostrem inicialmente ambíguas - e permaneçam como tais, mesmo nas decisões da CIJ.

\section{Referências}

ALMEIDA, Guilherme. A Proteção da Pessoa Humana no Direito Internacional. São Paulo: CLA, 2018.

ALEXY, Robert. Teoria da argumentação jurídica. São Paulo: Landy, 2001.

BADIN, Michelle; MOROSINI, Fabio; GIANNATTASIO, Arthur (org.). Direito internacional: leituras críticas. São Paulo: Almedina, 2019.

BERNSTORFF, Jochen. Martens Clause. In: WOLFRUM, R. The Max Planck encyclopedia of public international law. Oxford: Oxford University, 2012. v. 6.

CASELLA, Paulo. Fundamentos do direito internacional pósmoderno. São Paulo: Quartier Latin, 2008. 
DANN, Phillip; RIEGNER, Michael. The World Bank's Environmental and Social Safeguards and the Evolution of Global Order. Leiden Journal of International Law, v. 32, n. 3, p. 537-59, 2019.

DELMAS-MARTY, Mireille. Por um direito comum. São Paulo: Martins Fontes, 2004.

DUNANT, Henri. Un somvenir de Solferino. Genebra: Prodinnova, 2019.

FERNANDES, Raul. The United States and the Permanent Court of International Justice. New York: American Foundation, 192?.

GIANNATTASIO, Arthur. A Opinio Iuris Sive Necessitatis: do elemento subjetivo consuetudinário à intersubjetividade jurídica. In: CASELLA Paulo; RAMOS, André (org.). Direito internacional. São Paulo: Quartier Latin, 2009.

GIANNATTASIO, Arthur. A juridificação de conflitos políticos no direito internacional público contemporâneo: uma leitura política da paz pelo direito de Hans Kelsen a partir do pensamento político de Claude Lefort. Revista de Direito Internacional, v. 12, p. 57-76, 2016.

GIANNATTASIO, Arthur. Fundamentos de uma análise sociológica crítica das instituições jurídicas internacionais: negatividade e política na metodologia dos estudos em Direito Internacional no Brasil. Revista Brasileira de Estudos Políticos, v. 116, p. 113-158, 2018.

GIANNATTASIO, Arthur. Contra um fetichismo nos estudos empíricos em direito internacional: moldura intencional e o esvaziamento significativo da empiria. Revista de Estudos Empíricos em Direito, v. 5, p. 9-24, 2018.

GIANNATTASIO, Arthur. A favor de uma corte latino-americana de justiça: uma reação sobre a legalidade e a legitimidade de seu desenho institucional. Revista de Direito Internacional, v. 17, p. 14-18, 2020.

GIANNATTASIO, Arthur; BEZERRA, Tainá; BANNWART, Elizabeth; DREZZA, Débora; BUCHLER, Jéssica; CARDOSO, Giovana; OLIVEIRA, Breno. International Constitutional Court: rise and fall of an international debate. Revista de Direito Internacional, v. 16, p. 130-146, 2019.

GIANNATTASIO, Arthur, DREZZA, Débora; WEHBY, Maria. In: On applied legal research: pragmatic limits to the impact of peripheral international legal scholarship via policy papers. Leiden Journal of International Law, v. 34, n. 3, 2021.

HASKELL, John. From apology to utopia's condition of possibility. Leiden Journal of International Law, v. 29, n. 3, p. 667-676, 2016.

KELSEN, Hans. Pazppelo direito. São Paulo: Martins Fontes, 2010.

KENNEDY, David. The last treatise: project and person (reflections on Martti Koskenniemi's from apology to utopia). German Law Journal, v. 7, n. 2, p. 982-992, 2006.

KOSKENNIEMI, Martti. What should international lawyers learn from Karl Marx? Leiden Journal of International Law, v. 17, n. 2, p. 229-324, 2004.

KOSKENNIEMI, Martti. The fate of public international law: between technique and politics. Modern Law Review, v. 70, n. 1, p. 1-30, 2008.

KOSKENNIEMI, Martti. Entre a apologia e a utopia: a política do direito internacional. Revista de Direito Internacional, v. 15, n. 1, p. 5-29, 2018.

KOSKENNIEMI, Martti. A política do direito internacional: 20 anos depois. Revista de Direito Internacional, v. 15, n. 1, p. 30-40, 2018.

LIMA, Lucas Carlos. Da relevância dos casos de desarmamento nuclear perante a corte internacional de justiça. Revista de Direito Internacional, v. 14, n. 3, p. 202-15, 2017.

ONUMA, Yasuaki. Direito internacional em perspectiva transcivilizacional. Belo Horizonte: Arraes, 2016.

OKIMOTO, Keiichiro. The Distinction and Relationship between Jus ad Bellum and Jus in Bello. Oxford/Portland: Hart, 2011.

PAHUJA, Sundhya. The postcoloniality of international law. Harvard International Law Journal, v. 46, n. 2, p. 459-469, 2005.

RAIMONDO, Fabián. The international court of justice as a guardian of the unity of humanitarian law. Leiden Journal of International Law, v. 20, n. 3, p. 593-611, 2007.

RASULOV, Akbar. From apology to utopia and the inner life of international law. Leiden Journal of International Law, v. 29, n. 3, p. 641-666, 2016.

RORIZ, João; VEÇOSO, Fabia; TASQUETO, Lucas. A administração de territórios ocupados: indeterminação 
das normas de direito internacional humanitário? Revista de Direito Internacional, v. 10, n. 2, p. 183-195, 2013.

SALMÓN, Elizabeth. Introducción al derecho internacional bumanitario. Lima: Pontificia Universidad Católica del Peru, 2016.

SANCTIS, Adriane. América Latina em continuidades e rupturas. Revista de Direito Internacional, v. 14, n. 3, p. 285-9, 2017.

SKOUTERIS, Thomas. The notion of progress in international law. Hague: TMC, 2010.

SWINARSKI, Cristophe. Direito internacional humanitário. São Paulo: Revista dos Tribunais, 1990.

TRINDADE, Antônio. Os tribunais internacionais contemporâneos. Brasilia: FUNAG, 2013.

TICEHURST, Rupert. The Martens clause and the laws of armed conflict. International Review of the Red Cross, n. 317, 1997.

TOURME-JOUANNET, Emmanuelle. Le Droit International. Paris : PUF, 2016.

VIEHWEG, Theodor. Tópica e jurisprudência. Porto Alegre: Sergio Antonio Fabris, 2008. 
Para publicar na Revista de Direito Internacional, acesse o endereço eletrônico www.rdi.uniceub.br ou www.brazilianjournal.org.

Observe as normas de publicação, para facilitar e agilizar o trabalho de edição. 